\title{
Marine Propulsion by the Injection of Compressed Air
}

\author{
A. H. E. Gherouat ${ }^{1}$, L. Khochemane ${ }^{2}$, O. BENNIS ${ }^{3}$ \\ ${ }^{1}$ Mechanical Engineering Department, ${ }^{2}$ Department of petrochemical Engineering, \\ ${ }^{3}$ Multidisciplinary laboratory of mechanical and energetic system. \\ ${ }^{1}$ University of 20 Août 1955 Skikda ALGERIA, ${ }^{2}$ University of 20 Août 1955 Skikda ALGERIA, \\ ${ }^{3}$ University of Orleans FRANCE \\ ${ }^{1}$ hgherouat@gmail.com, ${ }^{2}$ lakhdarkhochmane@yahoo.fr, ${ }^{3}$ ouafae.bennis@univ-orleans.fr,
}

\begin{abstract}
Most of the variables which has an influence on the propulsion: the compression Ratio, for naval engine, water is a substance that has a very weak compression effect that for it is considered as an incompressible liquid, that effect directly the efficiency of propulsion and make it weaker, to make a biphasic mixture with mixing compressed air in water in form of bubbles injected, causes the relaxation which adds a complementary force of reaction for the primary force, by the way the existences of air bubbles creates an interruption in continuous environment which is water so it avoids the dissipation of the applied force by the blades and increases the reaction force.
\end{abstract}

Keywords: Boat, ship propulsion, hydrodynamics, resistance, friction, density, push, sea water, compressed air, injection

\section{INTRODUCTION}

The maritime propulsion does not know a great development compared to the other transportation, its development came with the development of engines which actuate the blades, an upgrading capability is possible intervening on the multiple parameters and elements in direct contact with maritime environment, this article presents a work to carry out on the factor of compressibility upstream is downstream from the propeller.

The maritime propulsion is the main tool of pushing used for boats, is also important to it to care of the load capacity that one boat can transport seen that it floats, this phenomenon explained by Archimedes as a force to push upwards like a reaction to the weight, on the other hand the displacement of the transportation is done according to the pushing by the reaction of the propeller and the force of resistance of the fluid, that for the weight does not make a problem what makes boat the best means of transport of merchandise, just remains the problem of resisting forces.

\section{RESistance ON THE BOAT}

Resistance is considered by the force $\mathrm{K}$, defined as the force exerted by the dynamic pressure of the water at the speed $\mathrm{V}$ of the boat on a surface which is equal to the wetted area of hull $\mathrm{A}_{\mathrm{S}}$ to multiply by a coefficient of friction relating to the type of force[1].

\section{A. Resistance of the air}

In calm weather, air resistance is proportional to the square of the speed boat and proportional to the section of the ship above the waterline. The air resistance is normally about $2 \%$ of the resistance against for container ships can be up to $10 \%$, even it represents $90 \%$ of the dynamic pressure of the air at the speed of the boat [2].

$\mathbf{R}_{\mathrm{A}}=\mathbf{C}_{\mathbf{A}} \mathbf{K}$

$K=\frac{1}{2} \rho V_{\text {boat }}^{2} A_{S}$

$R_{A}=0.90 \times \frac{1}{2} \times \rho_{\text {air }} \times V_{\text {boat }}^{2} \times A_{\text {air }}$

$\mathrm{C}_{\mathrm{A}}$ : Resistance coefficient related to the surface.

$\rho_{\text {air }}$ : Air density.

\section{B. Friction Resistance.}

The frictional resistance $R_{F}$ of the shell depends on the size of the wetted area of the hull, and Specific friction resistance coefficient $\mathrm{C}_{\mathrm{F}}$. The friction increases with the fouling of the hull, ie d. by growing, algae, sea grass and branches.

An attempt to prevent fouling of the hull is using antifouling paints to prevent the hull from becoming "long hair", it means that these paintings reduce the possibility that the hull becoming fouled by living organisms, When the vessel is propelled through the water, friction resistance increases at a rate proportional to the speed of the ship.

$\mathbf{R}_{\mathrm{F}}=\mathbf{C}_{\mathbf{F}} \mathbf{K}$ 
$\mathbf{C}_{\mathbf{F}}$ : Coefficient of friction relating to the friction resistance.

$C_{F}=\frac{0.075}{\left(\log R_{n}-2\right)^{2}}$

$\mathbf{R}_{\mathbf{n}}$ : Reynolds number.

$\mathbf{R}_{\mathbf{n}}=\frac{\mathbf{V}_{\text {boat }} \times \mathbf{L}_{\mathbf{w l}}}{\mathbf{v}}$

$\mathbf{L}_{\mathbf{w l}}$ : The length of line of undulation of the hull of boat [3].

$\mathbf{v}$ : Kinematic viscosity of water.

$v=\left[\left(43.4233-31.38 \times \rho_{\text {water }}\right) \times(T+20)^{1.72 \times \rho-2.202}+4.7478-5.779 \times \rho\right] \times 10^{-6}$

$\mathbf{T}:$ Temperature in Celsius degree.

C. Residual resistance:

The residual strength $R_{R}$ includes the wave of resistance and backwater resistance. The wave resistance is related to the energy loss caused by waves created by the ship during its propulsion through the water, while the resistance swirl refers to the loss caused by the flow separation that creates tub, in particular at the rear end of the boat.

$\mathbf{R}_{\mathbf{R}}=\mathbf{C}_{\mathbf{R}} \mathbf{K}$

$\mathbf{C}_{\mathbf{R}}$ : Coefficient of friction relating to residual resistance.

D. General resistance:

The total resistance which is the total force necessary of towing that it is necessary to exceed to make move the boat represented on the figure Fig. 1.

$\mathbf{R}_{\mathbf{T}}=\mathbf{R}_{\mathbf{A}}+\mathbf{R}_{\mathbf{F}}+\mathbf{R}_{\mathbf{R}}$
$\mathbf{R}_{\mathbf{T}}=\mathbf{R}_{\mathbf{A}}+\mathbf{R}_{\mathbf{F}}+\mathbf{R}_{\mathbf{W}}+\mathbf{R}_{\text {swirl }}$

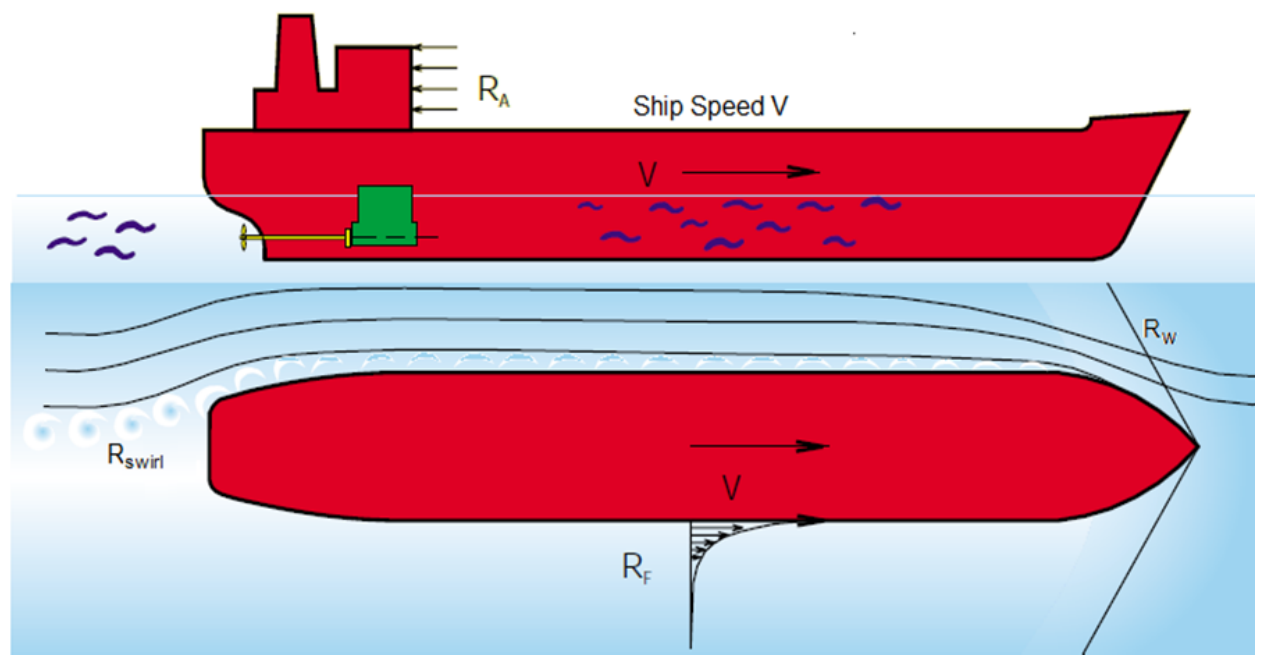

Fig. 1. Representation of the resistance forces applied on a boat.

III. JET PROPULSION:

Jet propulsion is a practical application of the third law of motion of Sir Isaac Newton states that 'each force acting on a body there is an equal and opposite reaction'. For the propulsion of vessels, the object is sea water which is supposed to accelerate as it flows through the propellant. The force required to give such acceleration has not equal effect in the opposite direction acting on the device producing the acceleration this is due to the amortization of the propulsion force spread. A propeller produces thrust of an engine / propeller combination. Both propel ships with a loud water weight back.

\section{A. Upstream Speed:}

IV. PARAMETER OF ENTRY

The input speed represents the speed of the liquid upstream of the engine it is equal at the speed of the boat compared to the propeller, considering the liquid is fixed and the engine moves at the same speed of the boat on the against downstream it is pushed by the propellant. 


\section{B. Upstream weight:}

Considering the position of the thruster on the back of the ship the volume of water at the inlet is relating to the diameter of the propeller, the boat's displacement requires moving of a volume equivalent to immersed volume except that it is not equal to the volume passing through the propellant, a large volume of water moves on the sides in the form of waves.

Then the mass of water in the propellant inlet is relative to volume at the nozzle inlet:

$$
\mathbf{M}_{\mathbf{1}}=\mathbf{V}_{\mathbf{1}} \times \mathbf{A}_{\mathbf{1}} \times \rho_{\text {water }}
$$

$\mathbf{M}_{\mathbf{1}}$ : Mass water at the entry of the propeller.

$\mathbf{V}_{\mathbf{1}}$ : Speed of water at the entry of the propeller. $\mathbf{V}_{\mathbf{1}}=\mathbf{V}_{\mathbf{b o a t}}$.

$\mathbf{A}_{\mathbf{1}}$ : The surface of entry of the nozzle.

C. Pressure:

The pressure of the water upstream of the engine is only the hydrostatic pressure proportional to the depth of the propellant seen that water at this stage has not yet undergoes any handling or application of force.

$\mathbf{P}_{\text {entry }}=\boldsymbol{\rho}_{\text {water }} \times \mathbf{g} \times \mathbf{h}_{\text {propeller }}$

$\mathbf{h}_{\text {propeller }}$ : Depth on the level of the engine.

g : The gravity.

RQ: the depth of vessels depends on the type of vessel it can reach $25 \mathrm{~m}$ for tankers (oil tankers) and $16 \mathrm{~m}$ for container carriers.

\section{Volume and mass flow :}

The volumetric flow of the propellant inlet is equal to the velocity of the water upstream (entrance) multiplied by the section to obtain the volume per unit of time, against the mass flow which represents the mass of water entered to the propellant is related to the density of the water and the volume flow.

$$
\begin{aligned}
& \mathbf{Q}_{\mathbf{V} 1}=\mathbf{A}_{1} \times \mathbf{V}_{\mathbf{1}} \\
& \mathbf{Q}_{\mathbf{M} 1}=\mathbf{Q}_{\mathbf{V} 1} \times \boldsymbol{\rho}_{\text {water }} \\
& \mathbf{Q}_{\mathbf{M} \mathbf{1}}=\mathbf{A}_{\mathbf{1}} \times \mathbf{V}_{\mathbf{1}} \times \boldsymbol{\rho}_{\text {water }}
\end{aligned}
$$

\section{INJECTION OF THE COMPRESSED AIR:}

Relaxation after a compression diffuse a useful force that gives a large force, water being an incompressible fluid is proposed injection of air as a compressible fluid, clean and does not chemically react with the water, so more air is pressurized its trigger releases a work ie. More strength. According to HENRY's law: "At constant temperature, the Quantity of gas dissolved in a liquid is proportional to the pressure exerted by the gas on the liquid," the parameters of this law require:

- If the temperature increases, dissolution decreases.

- Permanently when a gas is in contact with a liquid, it occurs an exchange between gas and dissolved gas.

- In balance, the exchanges are identical.

- The gas exerts a pressure on the liquid, and the liquid exerts a tension on gas.

- In this work the water is supposed to be saturated and the air does not undergo dissolution in water to neglect the loss of gas mass in the liquid.

\section{A. Description of the injection mechanism:}

For a good effectiveness of the air injection it should be made in the form of small bubbles with a good distribution in a homogeneous way to avoid the fusion of the bubbles, to achieve this task it is necessary for us that the injection should be done with the same frequency for all the points of injections.

\section{B. Site of the injection:}

The base of this study is made on the assumption that the engine is under conduit to eliminate the losses with the slip corresponding to dissipation of water on the sides, to make a decision on the site of the injectors Three (03) cases are possible:

\section{B.1. Upstream of the blades:}

For an engine with considerable power having an admission a propeller then an extraction the injection of a compressed gas causes a relaxation upstream and the water arriving from opposite of the boat thus it will create a resistant force on the engine and push the boat, except if the pressure of the air is not very large and lower than the resistant force of the liquid $\left(\mathrm{P}_{\text {air }}<\mathrm{P}_{\text {liquide }}\right)$ then the gas is the subject of a compression upstream and after he passes by the blade he begins his relaxation, therefore the disadvantage of fusion of the bubbles increases. 


\section{B.2. Downstream from the blades:}

With a great pressure, the gas begins its relaxation directly after its injection and releases energy allotted by the compressor in all the directions whereas at the same time it undergoes the force released by water coming from the propeller, and after the gas pressure decrease the dissolved bubbles between them and causes the braking of the liquid downstream from the propeller behind the boat, therefore that avoids the propagation of the forces, that transform them into reaction in additional forces for the push.

\section{B.3. On the same level of the blades:}

As long as the traditional engine has a classical blades cannot consider the possibility of placing the injectors on the same level of the blades considering the risks and disturbances which the bubbles of air can caused on the blades, as well as the erosion effects of the bubbles on surface of the blades and the ultrasounds which are caused by the disintegration and the relaxation of the bubbles.

The system of injection are constituted from an opening in the conduit downstream from the propeller allowing the repression of the compressed air, inside a small wheel having a vertical axis wind turbine within the same way of the air flow, between the blades of the small openings which allow the exit of the air, when the opening between blades coincides with the opening of the conduit.

With the air pressure which must be higher than the pressure of water the paddle wheel turns, with each time the opening of the conduit meet the opening between balding a volume of air is released after the engine.

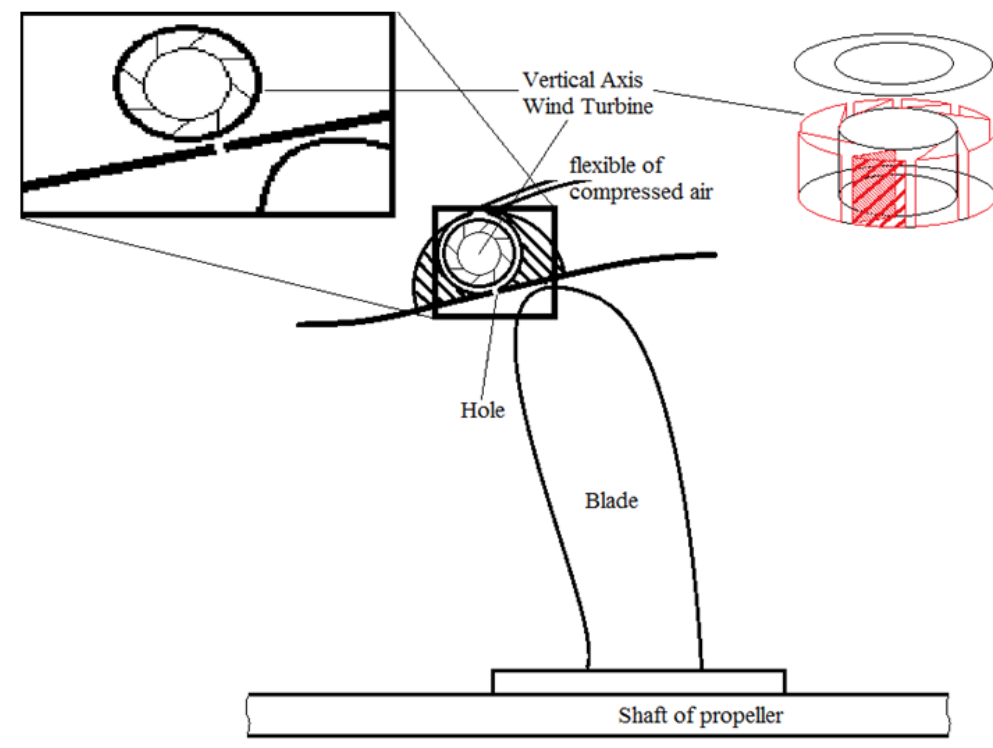

Fig. 2.Representation of the injection system of compressed air.

\section{Insulation of the system of injection:}

The utility of the insulation of the air injection system is carried out during starting, the stop or the deceleration, in these cases we must decrease the pressure of the air injected, knowing that if the pressure of the air will be lower than the pressure of water propelled, water returns in the circuit of air, to avoid the return which can deteriorate the wheels which fact the role to spray the bubbles with a uniform frequency, the insulation of the system is obligatory before that the air pressure decrease arriving to water pressure.

The system is made up of a cylinder which surrounds the engine between the openings of the engines and the air injection system to make the role of valve multi-ways, leak tight by O-ring seals in the two ends; it comprises openings like the conduit surrounding the engine to ensure the access of compressed air towards water.

The insulation of the circuit of air is done by the rotation of the cylinder on the axis of rotation of the engine the action occurs by a jack to go up on the external body of the engine, to hang to the cylinder which operate the role of a valve via a jack for double purpose which makes turn a cam to go up on an axis, the other end of the axis comprises another cam which itself push a tree which is fixed on the one hand on the cam and in the other on the cylinder, to transform the linear movement into rotation.

With the outlet of the jack of a small linear distance the cylinder turns and gives a perpendicularly position of these openings on those of the conduit engine and makes it possible the passage of the air bubbles in water downstream the engine, see (Fig. 3). 


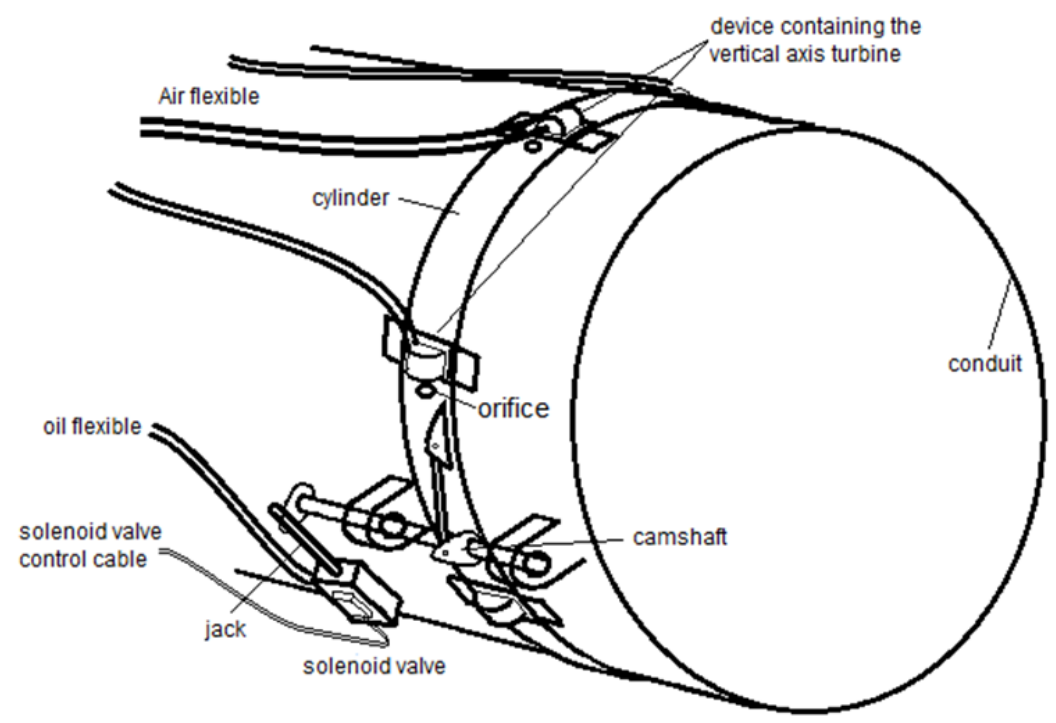

Fig. 3.Representation of the air insulation system.

VI. PARAMETER OF THE BUBBLES

\section{A. Handling of the parameters of the bubbles}

\section{A.1. Volume :}

The bubble being an outgoing quantity of air through a hole in the conduit, its volume is relating to the quantity of gas released, then related to the section of the opening of the hole and the volume locked up between two blades, and its pressure which can vary according to the tension of the liquid applied on the contour of bubble.

\section{A.2. Pressure:}

The pressure of the air bubble must be higher than the pressure of water so that it achieves the desired task on the other hand for its relaxation releases a force and energy to push the boat, this pressure decreases after its delivery with the relaxation.

The pressure of the air bubble in a point is relating to the interns pressure and the distribution of forces which determines its form, therefore in case of a spherical form, the compressive force in a point is relative to the nodimensional number proportional to the size length of the ray $\mathrm{R}$ equal in all points.

$$
\begin{aligned}
& \mathbf{P}=\frac{\mathrm{F}}{\mathrm{S}} \Rightarrow \mathbf{F}=\mathbf{P} . S \\
& \boldsymbol{\delta} \mathbf{F}=\mathbf{P} . \boldsymbol{\delta S} . \mathbf{R} \\
& \mathbf{R}=\mathbf{r} / \sum_{\boldsymbol{\theta}=\mathbf{n} \pi}^{\theta=\mathbf{r}} \mathbf{r}(\boldsymbol{\theta}) \\
& \mathbf{R}=\mathbf{r} / \int_{\mathbf{0}}^{\mathbf{n} \pi} \mathbf{r}(\boldsymbol{\theta}) \mathrm{d \theta}
\end{aligned}
$$

The phenomenon of creation of bubble of air is complicated summarizes by the creation of a gas-liquid interface usually with spherical forms which differs according to the distribution from the forces applied on it.

The liquid applies a force of tension or osmotic pressure which influences the air bubble according to the concentration of air in the water which causes the implosion and dissolution, these forces are functions of the volume of water surrounding the bubble, the air pressure of the bubble, the concentration of air in water and the both temperature.

The more the air pressure increases more dissolution of the air in water increases, more precisely the exchange between the air of the bubble and the air dissolved in water increases for that two bubbles close between them approaches and is linked in only one.

The compressive forces relating to the height of water thus modify the spherical shape of the air bubble and flattened seen that the density of the air definitely lower than that of water the bubble moves to the top but the force of pressure of water while coming from in top the growth downwards.

\section{A.3. Push of Archimedes:}

Any solid body completion immersed in a liquid in balance undergoes on behalf of the liquid an ascending vertical push whose intensity is equal to the weight of the moved liquid [4].

$\mathbf{P}_{\mathrm{A}}=\boldsymbol{\rho}_{\text {water }} \cdot \mathbf{V} \cdot \mathbf{g}$ 


\section{A.4. Frequency:}

The output frequency of the bubbles is relating to the pressure and the flow which determines the number of revolutions of the mechanism of injection as well as the number of cells limited by the blades which is the same number as the blades

$\mathbf{V}_{\text {injection }}=\mathbf{N}_{\text {blades }} \cdot \mathbf{V}_{\mathbf{r}}$

$\mathbf{V}_{\mathbf{r}}$ : Number of revolutions of the Vertical Axis Turbine in $\operatorname{tr} / \mathrm{min}$

$\mathbf{F}_{\text {injection }}=\frac{1}{\mathrm{~T}}[\mathrm{~Hz}]$

$T=\frac{60}{V_{\text {injection }}}=\frac{60}{\mathrm{~N}_{\text {blades }} \cdot V_{\mathbf{r}}}$

$F_{\text {injection }}=\frac{V_{\text {injection }}}{60}=\frac{N_{\text {blades }} \cdot V_{\mathrm{r}}}{60}$

$\mathbf{V}_{\mathbf{r}}=\frac{\mathbf{V}_{\text {linear }}}{2 \cdot \boldsymbol{\pi} \cdot \mathbf{r}}$

$\mathbf{V}_{\text {linear }}=\frac{\mathbf{Q} \mathbf{v}_{\text {air }}}{\mathbf{A}}$

$\mathbf{Q} \mathbf{v}_{\text {air }}=\mathbf{V}_{\text {linear }} \cdot \mathbf{A}$

A.5. Force pressure of the bubble:

The force of the bubble at the exit of the opening is function of the air pressure seen that the pressure is regulated via a tensioner and pressure regulator considering the pressure is fixed and the surface changes, therefore at the exit surface is a section and in water it is the surface of the bubble.

$\mathbf{P}_{\text {air }}=\frac{\mathbf{F}_{\mathbf{1}}}{\mathbf{A}_{\text {orifice }}}$

$F_{\text {bubble }}=P_{\text {air }} \times S_{\text {bubble }}$

$F_{\text {bubble }}=\frac{F_{1}}{A_{\text {orifice }}} \times S_{\text {bubble }}$

$\mathbf{A}_{\text {orifice }}$ : Orifice section Surface.

$S_{\text {bubble }}$ : Bubble Surface.

B. Compressor:

The injection of the compressed air is supplied via an air centrifugal compressor for assured a continuous flow whereas the pressure is not large enough; if it is necessary two (02) pistons compressor with an accumulator has size to be able to ensure the flow during the filling of the second.

\section{Recommendations of injection}

The pressure of the gas $P_{\text {air }}$ should not be very low so that the bubbles do not dissolve in the water which is not too deep and doesn't assembled between them to form large bubbles, the creation of these last gives multiple geometrical forms nonconventional that influences on the balance of the direction of the compressive force vector.

The small size of the bubbles is recommended to ensure a small flow, longer, and under pressure ensured by dimensions of the openings and the frequency cutoff on one hand and on the other hand the dimensions have to avoided the fusion of the bubbles between them even the maximum of time to ensure the relaxation in a small volume and a great diffusion of forces considering attraction between the bubbles under the effect of dissolution of the bubbles and the exchange of matter between them; Homogeneity of the mixture of the bubbles of air with water to ensure a good distribution of the forces just downstream from the engine.

\section{Risks Of The Injection Of A Gas On An Engine}

In the cases of dissatisfaction of the recommendations mentioned previously, several problems can appear:

- The vibrations by the axial movement of the shaft of the engine which appear in the extremities stages in the case of a bad distribution from the injectors, the blades pass by zones of various pressures.

- Risks of vibrations on the shaft of the engine which appear after demonstration in all the stages in the case of the injection close to the blades (and even in the other cases of injection quoted previously upstream of the blades), for reason of the unbalance effect caused by the bad distribution of the bubbles.

- The effect of erosion of surfaces of the blades whenever the injection is close to the blades with large bubbles, even in the case of injection upstream of the blades the bubbles must be very small.

- In the case of air injection upstream, the possibility of accumulating bubbles and their fusion increases and causes two (02) complications the first already quoted that is the unbalance which appears by the vibrations 
and the second one of gas stopper which increases resistance applied upstream ship if the pressure of the air is not suitable and low.

- the reaction force with the existence of the bubbles:

- In recall of the consequences acquired by our work applied on the propulsion system, the cloud of bubbles causes a resistance to the transmission of the propulsion forces downstream from the engine, it means an interruption of the continues environment which is water thus the potential energy which will not be transmitted all, it will be mainly absorbed by the air bubbles if the force of its pressure is lower, the bubble is compressed then it releases this energy in the form of work of relaxation, or it there transforms mainly into a reaction force (to push) if the compressive force of the bubble is higher or equal to the force of propulsion.

- Thus in total the usual propulsion increases its force of reaction in addition to the reaction resulting from the relaxation of the air bubbles.

\section{A. The downstream weight:}

\section{PARAMETER OF EXIT}

The quantity of matter on the outlet side of the engine is the quantity of water in suction plus the compressed air added except that the air volume changes and increases, this leaves the same quantity of matter according to two parameters (volume, pressure) which change.

$M_{2}=M_{\text {water }}+M_{\text {air }}$

$M_{2}=M_{1}+n_{\text {air }} \times M_{\text {air }}$

$M_{\text {air }}$ : Air mass.

$\boldsymbol{M}_{\text {air }}$ : Air molar mass: $29 \mathrm{~g} / \mathrm{mol}$.

$\boldsymbol{n}_{\text {air }}$ : Molar quantity of the mixture of air.

$\boldsymbol{n}_{\text {air }}=\frac{\boldsymbol{P}_{\text {bubble }} \times V_{\text {bubble }}}{\boldsymbol{R} \times \boldsymbol{T}_{\text {bubble }}}$

$\boldsymbol{P}_{\text {bubble }}$ : Air bubble pressure.

$V_{\text {bubble }}$ : One bubble volume.

$\boldsymbol{T}_{\text {bubble }}$ : Bubbles temperature.

$\boldsymbol{R}$ : Ideal gas coefficient.

$M_{2}=M_{1}+\frac{P_{\text {bubble }} \times V_{\text {bubble }}}{R \times T_{\text {bubble }}} \times M_{\text {air }}$

B. Mass flow:

$Q_{M 2}=A_{2} \times V_{2} \times \rho_{(\text {mixture })}$

$Q_{M 2}=M_{2} \times V_{2}=\left(M_{\text {water }}+M_{\text {air }}\right) \times V_{2}$

$\boldsymbol{V}_{2}$ : Fluid speed downstream the propeller.

C. The downstream speed :

Downstream speed of the engine is the speed of the mixture water and air; therefore it is function of two speeds, of water and the air.

$V_{2}=f\left(V_{\text {water }}, V_{\text {air }}\right)$

The speed of water on the outlet side of the engine is calculated by the number of revolutions of the engine as well as the global pitch of the propeller knowing that the pitch of a propeller changes at each distance to move away from the center of the engine is function of the angle of slope.

$\boldsymbol{V}_{\text {water }}=\boldsymbol{P}_{\text {prop }} \times \boldsymbol{n}_{\text {prop }} \times \boldsymbol{G}$

$\boldsymbol{P}_{\text {prop }}$ : Theoretical pitch of the propeller.

$\boldsymbol{n}_{\text {prop }}$ : Propeller rotation speed.

$\boldsymbol{G}$ : Slip.

$V_{\text {air }}=\frac{Q_{M_{\text {air }}}}{n_{i} \times A_{i} \times \rho_{\text {bubble }}}$

$\rho_{\text {bulle }}=\frac{M_{\text {bubble }}}{V_{\text {bubble }}}=\frac{\frac{P_{\text {bubble }} \times V_{\text {bubble }}}{R \times T_{\text {bubble }}} \times M_{\text {air }}}{V_{\text {bubble }}}=\frac{P_{\text {bubble }} \times M_{\text {air }}}{R \times T_{\text {bubble }}}$

$\boldsymbol{n}_{\boldsymbol{i}}$ : Number of air injection holes.

$\boldsymbol{A}_{\boldsymbol{i}}$ : Sectional area of an air injection holes. 


$$
\begin{aligned}
& \text { Eq. } 37=>\boldsymbol{Q}_{\boldsymbol{M} 2}=\left(\boldsymbol{M}_{\text {water }}+\boldsymbol{M}_{\text {air }}\right) \times \boldsymbol{V}_{2}=\boldsymbol{M}_{\text {water }} \times \boldsymbol{V}_{\text {water }}+\boldsymbol{M}_{\text {air }} \times \boldsymbol{V}_{\text {air }} \\
& \boldsymbol{V}_{2}=\frac{\boldsymbol{M}_{\text {water }} \times \boldsymbol{V}_{\text {water }}+\boldsymbol{M}_{\text {air }} \times \boldsymbol{V}_{\text {air }}}{\boldsymbol{M}_{\text {water }}+\boldsymbol{M}_{\text {air }}} \\
& \text { D. Volume flow: }
\end{aligned}
$$

The downstream volume flow of the engine is relating at the surface of the conduit on the exit of the engine and the liquid speed which is the speed of the boat plus the speed which is given by the energy transformation by the engine towards water.

$Q_{V 2}=A_{2} \times V_{2}$

$\boldsymbol{A}_{2}$ : The exit surface of the conduit.

\section{E. Relaxation effect :}

The relaxation effect is the base of this activity because it develops a work when the bubbles changes their volume increasing, to facilitate these calculations we suppose that the shape of the bubble remains spherical to simplify the calculation of volume, thus we considers that the air has the reaction of perfect gas [5].

$\mathbf{P} \times \mathbf{V}=\mathbf{n} \times \mathbf{R} \times \mathbf{T}$

At the beginning when $\mathrm{P}_{\text {air }}>\mathrm{P}_{\text {water }}$ the bubble slackens on the same level of the engine, therefore released work will have effect of a force of pushed on the surface projected of the engine.

$\mathbf{V}=\frac{\mathbf{n} \times \mathbf{R} \times \mathbf{T}}{\mathbf{P}_{\mathrm{air}}}$

Thus in this stage the ray changes according to the decrease of the air pressure.

$$
\mathbf{R}(\mathbf{h})=\sqrt[3]{\frac{\mathbf{n} \times \mathbf{R} \times \mathbf{T}}{\frac{4}{3} \times \boldsymbol{\pi} \times \mathbf{P}_{\mathrm{air}}}}
$$

After equality between the air pressure and water $\mathrm{P}_{\mathrm{air}}=\mathrm{P}_{\text {water }}$ the bubble slackens according to the height and its relaxation gives effect on the projected surface of the ship.

$$
\begin{aligned}
& \mathbf{P}_{\text {in }} \times \mathbf{V}_{\text {in }}=\mathbf{P}(\mathbf{h}) \times \mathbf{V}(\mathbf{h}) \\
& \mathbf{P}_{\text {in }}=\mathbf{P}_{\text {atm }}-\boldsymbol{\rho}_{\text {water }} \times \mathbf{g} \times \mathbf{h}_{\text {in }} \Rightarrow \mathbf{P}(\mathbf{h})=\mathbf{P}_{\text {atm }}-\boldsymbol{\rho}_{\text {water }} \times \mathbf{g} \times \mathbf{h} \\
& \mathbf{h}_{\text {in }}=\mathbf{z}: \text { Depth of the engine. } \\
& \mathbf{V}_{\text {in }}=\frac{4}{3} \times \pi \times \mathbf{R}^{3} \Rightarrow \mathbf{V}(\mathbf{h})=\frac{4}{3} \times \pi \times \mathbf{R}(\mathbf{h})^{3} \\
& \left(\mathbf{P}_{\text {atm }}-\boldsymbol{\rho}_{\text {water }} \times \mathbf{g} \times \mathbf{z}\right) \times\left(\frac{4}{3} \times \pi \times \mathbf{R}^{3}\right)=\left(\mathbf{P}_{\text {atm }}-\boldsymbol{\rho}_{\text {water }} \times \mathbf{g} \times \mathbf{h}\right) \times\left(\frac{4}{3} \times \boldsymbol{\pi} \times \mathbf{R}(\mathbf{h})^{3}\right) \\
& \mathbf{R}(\mathbf{h})=\sqrt[3]{\frac{\left(\mathbf{P}_{\text {atm }}-\boldsymbol{\rho}_{\text {water }} \times \mathbf{g} \times \mathbf{z}\right) \times\left(\frac{4}{3} \times \pi \times \mathbf{R}^{3}\right)}{\frac{4}{3} \times \pi \times\left(\mathbf{P}_{\text {atm }}-\boldsymbol{\rho}_{\text {water }} \times \mathbf{g} \times \mathbf{h}\right)}}
\end{aligned}
$$

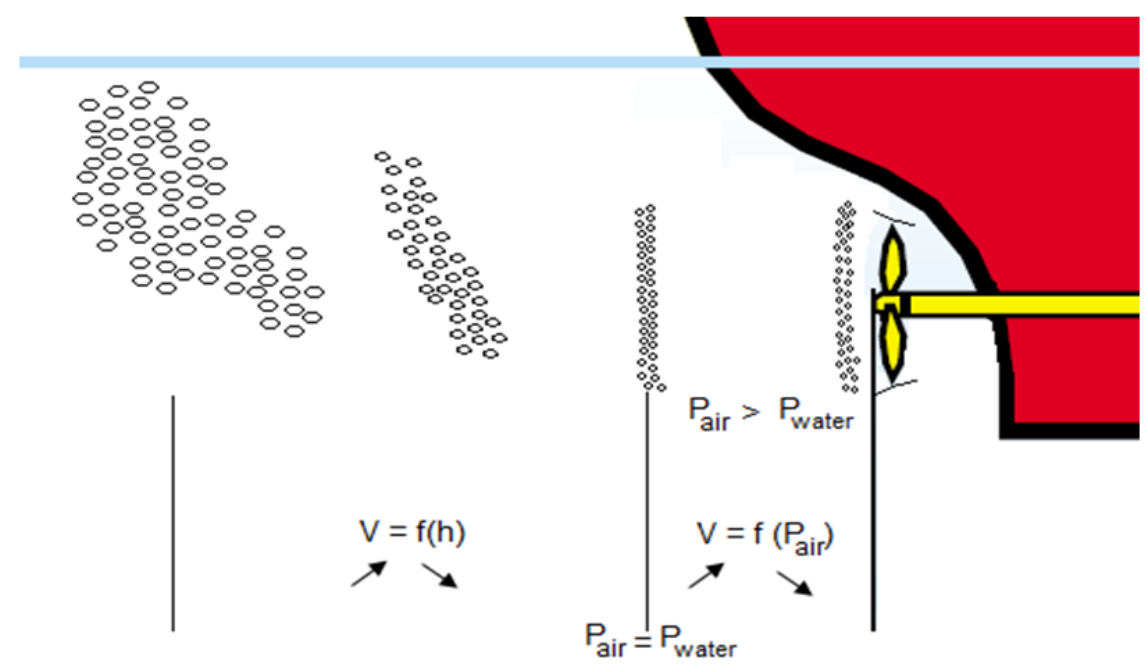

Fig. 4.Representation of the relaxation of the bubbles according to the air pressure and the height. 


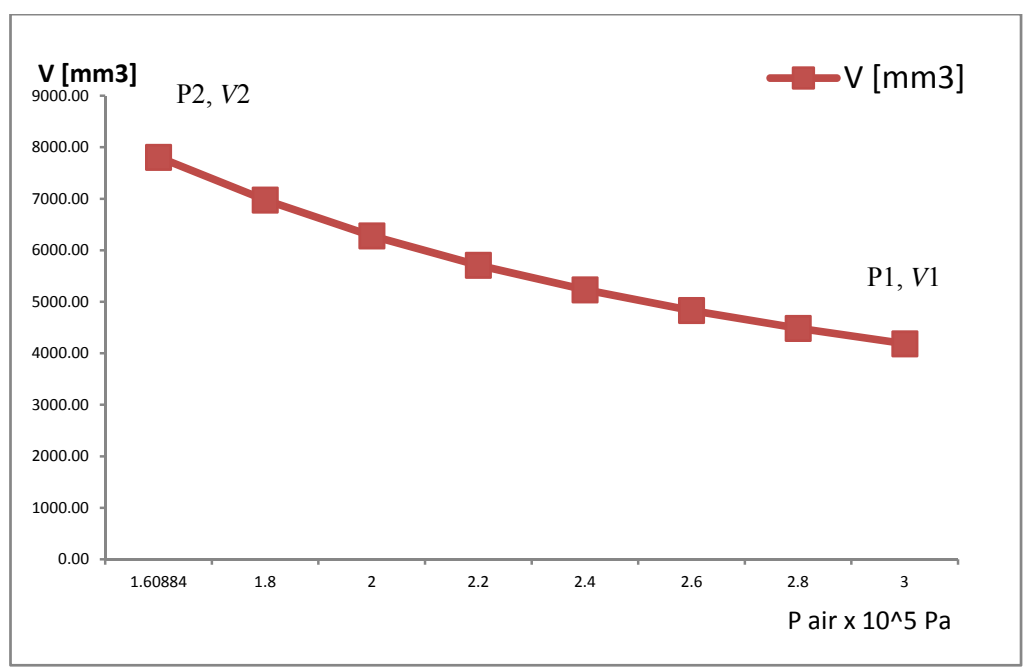

Fig. 5.Evolution of the isothermal relaxation according to the air pressure.

The relaxation at constant temperature saying isothermal gives a work $\mathrm{W}$

$\mathbf{W}=\mathbf{P}_{\mathbf{1}} \mathbf{V}_{\mathbf{1}} \times \ln \frac{\mathbf{V}_{\mathbf{1}}}{\mathbf{v}_{\mathbf{2}}}$

Considering the conditions following the depth of the engine $\mathrm{h}=16 \mathrm{~m}, \mathrm{~T}=15^{\circ} \mathrm{C}=288^{\circ} \mathrm{K}, \rho_{\text {water }}=1025$ $\mathrm{Kg} / \mathrm{m} 3, \mathrm{~g}=9.81 \mathrm{~N} / \mathrm{Kg}, \mathrm{P}_{\text {air } 1}=3 \mathrm{bar}=300000 \mathrm{~Pa}, \mathrm{R}_{\mathrm{ini}}=10 \mathrm{~mm}, \mathrm{R}=8,3144 \mathrm{~J} \times \mathrm{mol}^{-1} \times{ }^{\circ} \mathrm{K}^{-1}$.

At $\mathrm{P}_{\text {air } 1}, \mathrm{~V}_{1}=4,186 \times 10^{-6} \mathrm{~m}^{3}$, à $\mathrm{h}=16 \mathrm{~m}, \mathrm{P}_{2}=160884 \mathrm{~Pa}, \mathrm{~V}_{2}=7.806 \times 10^{-6} \mathrm{~m}^{3}, \mathrm{n}=0.00052452 \mathrm{~mol}$.

$\mathrm{M}_{\mathrm{air}}=0.01521111 \mathrm{~g}, \mathrm{~W}=-26.8110341 \mathrm{~J}$.

Therefore any bubble releases a work view that $\mathrm{W}<0$.

\section{F. Couple:}

To employ the power provided by the package (engine) to propel the ship it must turn the shaft connecting between the engine and the propeller. The power into horses generated by the engine to the shaft is applied as rotary force (or moment) transmitted to the propeller. This rotary force necessary to turn the axis is simply the couple [6].

$\boldsymbol{C}=\boldsymbol{F}_{\text {engine }} \times \boldsymbol{R} \times$ length

When the power is given in horses (HP: Horse power) the couple is found:

$P_{\text {thrust }}=5252 \times \frac{P_{\text {engine }}}{\omega} P_{\text {engine }}[\mathbf{c h}], \omega[\mathrm{tr} / \mathrm{min}]$

C : Couple.

$\mathbf{F}_{\text {engine }}$ : Engine Force .

$\boldsymbol{\omega}$ : Angular velocity.

$\mathbf{P}_{\text {engine }}$ : Power engine.

G. Useful Coefficients:

G.1. Advance coefficient:

$\mathbf{J}=\frac{\mathbf{V}_{\mathbf{1}}}{\mathbf{N} \times \mathbf{D}}$

$\mathbf{N}$ : Number of revolutions in tr/sec.

G.2. Pushing coefficient:

$\mathbf{K}_{\mathbf{t}}=\frac{\mathbf{P}_{\text {thrust }}}{\rho_{\text {water }} \times \mathbf{N}^{2} \times \mathbf{D}^{2}}$

$\mathbf{C}_{\mathbf{t}}=\frac{2 \times \mathbf{P}_{\text {thrust }}}{\rho_{\text {water }} \times \mathbf{A} \times \mathbf{V}_{\mathbf{1}}{ }^{2}}$

H. Transmission of effort in water

The transmission of the forces quoted previously is done by a transformation into oscillating waves in the marine environment; these oscillations are modelized by differential equations defining all the parameters such as the propagation velocity, damping, the amplitude ...

The existence of obstacle in water causes the reflection of the waves, like the air bubble permanently forms a cloud in the back of the ship; they rebound the efforts of propulsion applied by the ship. 


\section{Force :}

Contrary to the classic system which constituted thrust forces and reaction of the push, the forces applied in our system are growing around the air bubbles mainly and the ship, which are: the weight of the bubbles, the push of Archimedes, the hydrostatic pressure the push of the engine, the force of friction with a coefficient (c), the last one is very complex sight the parameters which influence and it represents viscous friction and the damping of transmission of the forces.

Considering a factor of reaction which is opposite function of the coefficient of friction:

\section{Rea $=(1-c) \sum$ Thrust forces}

Considering a factor of reflection (r) which have places during the exposure of a wave to an obstacle, in our case the bubbles of air, then a force which is propagated when it meets a bubble of air a part will be absorbed by the bubble if its force is lower than that released by the bubble (the bubble receives a work and this compresses) and the other part is reflected.

$\mathbf{r}+\mathbf{c}=\mathbf{1}$

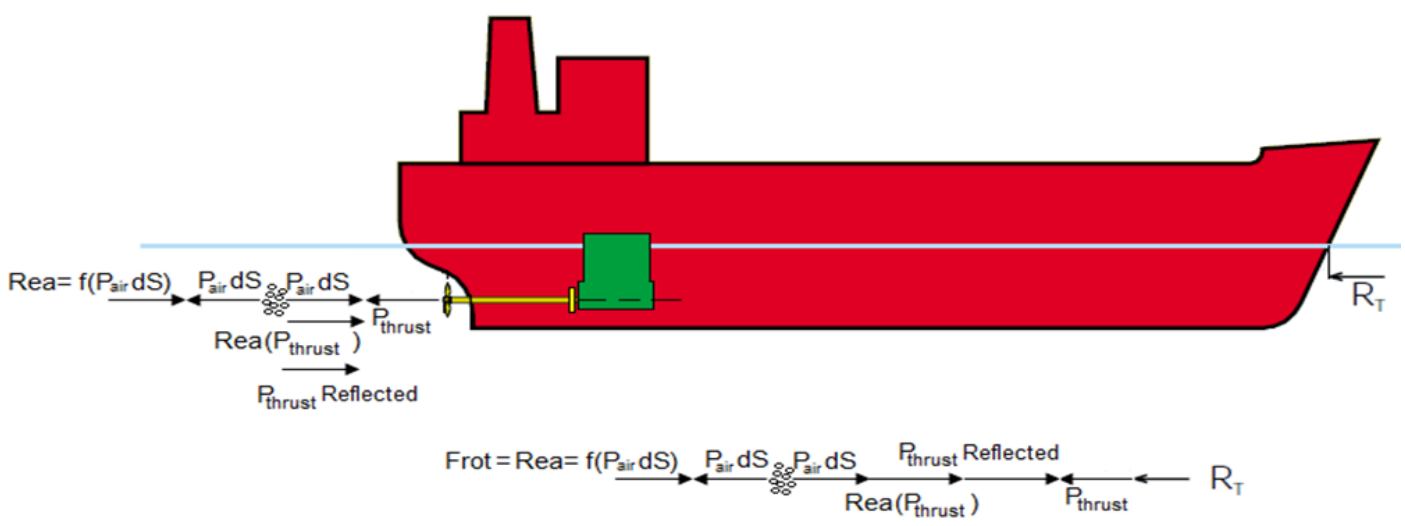

Fig. 6. Representation of the assessment of the forces applied to the ship.

According to this figure the force assessment represents all the projected forces which influence the displacement of the ship, imposition to specify that the air bubbles develop forces in the two directions, therefore the driving forces are the push and relaxation in the direction of the push, a resistant force in front of the boat and the forces of propulsion which are mainly the reaction force of the relaxation of the air bubbles, thrust reaction (the pushed reaction after the cloud of bubble is to neglect as loss), the push forces reflects and the force of relaxation in the direction of advance of the boat.

$\overrightarrow{\operatorname{Rea}}+\overrightarrow{P_{\text {air }} \times d \boldsymbol{S}}+\overrightarrow{\operatorname{Rea}\left(\boldsymbol{P}_{\text {thrust }}\right)}+\overrightarrow{\mathbf{P}_{\text {thrust }}(\text { Reflected })}-\overrightarrow{\mathbf{P}_{\text {thrust }}}-\overrightarrow{\mathbf{R}_{\mathrm{T}}}-\overrightarrow{\mathbf{P}_{\text {air }} \times \mathbf{d S}}=\mathbf{M} \times \mathbf{a}(60)$
$\frac{1}{\mathrm{c}} \times\left(\mathbf{P}_{\text {air }} \times \mathbf{d S}\right) \mathbf{V}_{2}+\mathbf{P}_{\text {air }} \times \mathbf{d S}+\frac{1}{\mathrm{c}} \times\left(\mathbf{P}_{\text {thrust }}\right) \mathbf{V}_{2}+\frac{1}{\mathrm{r}} \times\left(\mathbf{P}_{\text {thrust }}\right)-\mathbf{P}_{\text {thrust }}-\mathbf{R}_{\mathrm{T}}-\mathbf{P}_{\text {air }} \times \mathbf{d S}=\mathbf{M} \times \mathbf{a}(61)$

We neglect the forces which apply after the bubbles considering the speed of the liquid moving far away decrease, therefore:

$\mathbf{P}_{\text {air }} \times \mathbf{d S}+\frac{1}{\mathrm{c}} \times\left(\mathbf{P}_{\text {thrust }}\right) \mathbf{V}_{2}+\frac{1}{\mathrm{r}} \times\left(\mathbf{P}_{\text {thrust }}\right)-\mathbf{P}_{\text {thrust }}-\mathbf{R}_{\mathrm{T}}=\mathbf{M} \times \mathbf{a}$

J. power and efficiency:

The propelling efficiency of the classical engines is calculated by [7]:

$\boldsymbol{\eta}_{\text {tot }}=\frac{\left(\mathbf{R}_{\mathbf{t}} \times \mathbf{V}_{\text {boat }}\right)}{2 \times \boldsymbol{\pi} \times \mathbf{N} \times \mathbf{C}_{\text {shaft }}}$

$\mathbf{C}_{\text {shaft }}$ : Engine shaft couple.

Considering the applied forces are the thrust and damped reaction

For the current case:

$$
\begin{aligned}
& \boldsymbol{\eta}_{\text {tot }}=\frac{\text { Power }_{\text {developed }}}{\text { Power }_{\text {spent }}} \\
& \boldsymbol{\eta}_{\text {tot }}=\left(\left(\mathbf{P}_{\text {air }} \times \mathbf{d S}+\mathbf{1} / \mathbf{c} \times\left(\mathbf{P}_{\text {thrust }}\right) \mathbf{V}_{-} \mathbf{2}+\mathbf{1} / \mathbf{r} \times\left(\mathbf{P}_{\text {thrust }}\right)-\mathbf{P}_{\text {thrust }}-\mathbf{R}_{\mathbf{T}}\right) \times \underset{(65)}{(64)}\right) /((2 \times \boldsymbol{\pi} \times \mathbf{N} \times \\
& \left.\left.\mathbf{C}_{\text {shaft }}\right)+ \text { Power }_{\text {compresor }}\right)
\end{aligned}
$$




\section{CAVITATIONS EFFECT:}

Cavitations is generated during the creation of the bubbles due to a decompression behind the blades, according to the cavitations formula the coefficient of cavitations will have a significant value when the pressure of water is higher than that of the bubbles, then with the injection of the compressed air with a pressure superior than that of water, the injected bubble does not present any effect of cavitations and the relaxation of this pressure decreases its effect with the compensation of pressure.

\section{Conclusion}

The considerable increase of the reaction efforts of the propulsion forces ensured by the permanent deposition of obstacle which will be useful as a separation in a continuous environment which is the sailor environments by a cloud of air bubbles, it gives use to the reflection of the forces applied and thus forbids their transmissions, decreases the losses and gives supports for the forces.

The propulsion still encounters difficulty in spite of the efforts of the researchers in the hydrodynamic optimization of the shapes of the hulls of the ships whereas projected surface of immersed part remainder large, the intervention on the form of the immersed part of ship is in the prospects for reducing the water drag effect on the boats.

\section{REFERENCES}

[1] Resistance and Propulsion of Ships, Sv. Aa. Harvald, 1983

[2] Ship Resistance H.E. Guldhammer and Sv. Aa. Harvald, 1974.

[3] Prediction of Resistance and Propulsion Power of Ships. Project no. 2010-56, Emissionsbeslutningsstøttesystem Work Package 2, Report no. 04. May 2013.

[4] James Stewart, Calculus: Concepts and Contexts, Cengage Learning, 2009, 4th edition.

[5] Bulles d'air dans l'eau : couplage d'oscillateurs harmoniques et excitation paramétrique. V. LEROY Doctoral thesis 2004

[6] E. C. TUPPER Introduction to Naval Architecture, 3rd edition, 2002.

[7] Hydrodynamics for Ocean Engineers. Prof. A.H. Techet. 2004.

\section{Author Profile}

GHEROUAT Ahmed Houssem Eddine : Electromechanical Engineer, on June 2007 from University of 20 Août 1955 Skikda ALGERIA, Magister degree on mechatronic engineering on 2010 from University of 20 Août 1955 Skikda ALGERIA, procurement engineer from Algerian Petroleum institute of Boumerdes on 2011. Research Focus: Propulsion and Energy.

Khochemane Lakhdhar : Doctorate in Electromechanical Engineering.Option : Maintenance. Research Focus: Tribology, mining and drilling, electromechanical engineering.

BENNIS ouafae : Doctorate in automatic Engineering..Research Focus: automatic control. She is a member of the PRISME laboratory of the University of Orléans (PRISME: Laboratoire Pluridisciplinaire de Recherche en Ingénierie des Systèmes, Mécanique et Energétique, Université d'Orléans) 